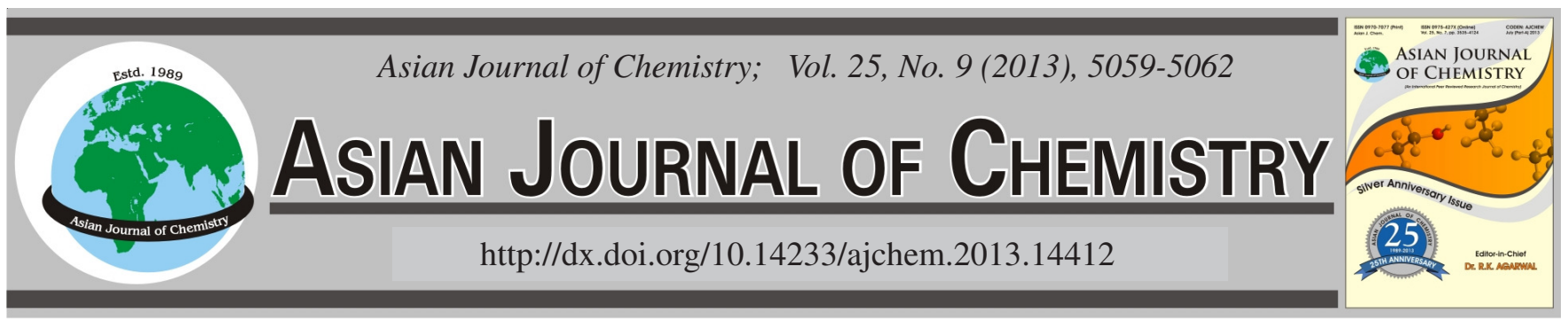

\title{
Reductive Fixation of Carbonate in Aqueous Solution by Nitrogen Plasma
}

\author{
T. Munegumi ${ }^{1,2, *}$ and K. Harada ${ }^{3}$
}

${ }^{1}$ Department of Science Education, Naruto University of Education, Naruto, Tokushima 772-8502, Japan

${ }^{2}$ Oyama National College of Technology, Oyama, Tochigi 323-0806, Japan

${ }^{3}$ Department of Chemistry, University of Tsukuba, Tsukuba, Ibaraki 305-8577, Japan

*Corresponding author: Fax: +81 88 6876022; Tel: +81 88 6876418; E-mail: tmunegumi@naruto-u.ac.jp; toramune@gmail.com

A jet of nitrogen plasma blown into a sodium carbonate solution produced reductive fixation of carbonate to formate. The reaction is explained by the nitrogen-mediated oxidation-reduction of water.

Key Words: Reductive fixation, Carbonate, Formate.

\section{INTRODUCTION}

The atmospheric composition of primitive earth has been discussed for many years. Many chemists had believed that the primitive atmosphere of the earth was "reducing" $\left(\mathrm{NH}_{3}\right.$, $\mathrm{CH}_{4}, \mathrm{H}_{2}$ and $\left.\mathrm{H}_{2} \mathrm{O}\right)^{1}$, while most geochemists have emphasized that the atmosphere was "nonreducing" $\left(\mathrm{N}_{2}, \mathrm{CO}_{2} \text { and } \mathrm{H}_{2} \mathrm{O}\right)^{2-6}$. The production of organic compounds from $\mathrm{N}_{2}, \mathrm{CO}_{2}$ and $\mathrm{H}_{2} \mathrm{O}$ is difficult because of the thermodynamic disadvantage (Scheme-I). Stribling and Miller examined ${ }^{7}$ the effect of electric discharge (Miller discharge ${ }^{1}$ ) into gas mixtures possessing different concentrations of carbon dioxide, methane and hydrogen and plotted the relationship between the initial gaseous ratio and carbon yield of organic compounds produced. The carbon yield became lower with higher concentrations of carbon dioxide without hydrogen. These results demonstrate that under discharge electrolysis, the reduction of organic compounds is difficult without hydrogen.

$$
\begin{aligned}
& \mathrm{CO}_{2}+2 \mathrm{H}_{2} \mathrm{O} \longrightarrow \mathrm{CH}_{4}+2 \mathrm{O}_{2} \quad \Delta \mathrm{G}_{298}^{\mathrm{o}}=802 \mathrm{~kJ} / \mathrm{mol} \\
& \text { Scheme-I }
\end{aligned}
$$

Nevertheless, in early years of the last century, $\mathrm{Löb}^{8}$ and Groth et al. ${ }^{9}$ confirmed the production of formate aldehydes from carbon dioxide and water vapor without hydrogen by silent discharge ${ }^{8}$ or irradiation by ultraviolet light ${ }^{9}$. The formation of formate and formaldehyde by irradiation of aqueous solutions of carbon dioxide with a $\mathrm{He}^{2+}$ beam (40 $\mathrm{MeV}$ ) is also possible ${ }^{10}$. Aqueous solutions containing carbon dioxide were irradiated in the presence (yield of formate, $22 \%$; formaldehyde, $0.34 \%$ ) or in the absence (yield of formate,
$0.14 \%$; formaldehyde, $2.8 \times 10^{-4} \%$ ) of ferrous sulphate. The yield of formate in the absence of ferrous sulphate was much lower, even though the reaction was conducted using higher energy radiation. The observation suggests the importance of the combination of carbon dioxide, water vapour, energy sources and/or agents for reducing carbon dioxide. Chemical evolution on primitive earth and extra terrestrial formation of organic compounds is highlighted by these findings.

In contrast, Folsome et al. ${ }^{11}$ examined electric discharge in molecular nitrogen over an aqueous solution of calcium carbonate in the presence of $\mathrm{Fe}^{2+}$. Nitric acid, nitrous acid, ammonia and carbonate hydrazine were obtained, but formate was not. They commented that molecular nitrogen served as the primary oxidant scavenger, leading to the formation of nitrite and nitrate.

If an aqueous solution is irradiated with nitrogen plasma containing nitrogen radicals, the high energy conditions will dissociate water molecules into hydroxyl $(\mathrm{OH})$ and hydrogen (H) radicals (Scheme-II) and these radicals will react with nitrogen radicals in the plasma. The dissociation of water molecules by glow discharge electrolysis (Harada discharge) onto aqueous solutions and blowing a jet of argon plasma into water has already been proven by Hase and Harada ${ }^{12,13}$. Reductive fixation of carbon dioxide or carbonate has not been reported, although reductive fixation ${ }^{14-17}$ of nitrogen by nitrogen-argon plasma and reduction ${ }^{18}$ of carbon-carbon double bonds in maleic acid by hydrogen-argon plasma have been reported $^{14-18}$.

$$
\mathrm{H}_{2} \mathrm{O} \longrightarrow \mathrm{H}^{\prime}+{ }^{\circ} \mathrm{OH} \quad \Delta \mathrm{G}^{\mathrm{o}}{ }_{298}=475 \mathrm{~kJ} / \mathrm{mol}
$$


In this paper, we describe the formation of formate from sodium carbonate in an aqueous solution induced by nitrogen plasma as a model reaction for nonreducing atmospheric conditions. Under nonreducing conditions, higher energy plasma could be generated by the action of lightning, atmospheric entry of meteors and meteorites or by radiation of solar winds or cosmic rays on the primitive ocean ${ }^{2-4}$.

\section{EXPERIMENTAL}

Sodium carbonate and ammonium phosphate were purchased from Wako Pure Chemical Industries Ltd. (Tokyo). Chemicals for making buffer solutions: potassium gluconate, pyroborate, acetonitrile and glycerin were purchased from Tokyo Chemical Industry Co. Ltd. (Tokyo).

Reaction apparatus and method: The apparatus for the reaction induced by nitrogen plasma is shown in Fig. 1. A plasma jet generated by electric discharge through a stream of nitrogen-argon gas mixture was used as an energy and nitrogen source for the reactions. A Well Pen PLA-J (Nippon Welding Co. Ltd.) was used as a plasma generator. The flow of nitrogenargon was controlled at $2.0 \mathrm{~L} / \mathrm{min}$. A sample was removed from the reaction mixture for analysis every $10 \mathrm{~min}$. Nitrogenargon arc plasma (the nitrogen-argon flow rate: $0.0,2.0 ; 0.5$, $1.5 ; 1.0,1.0 ; 2.0,0.0 \mathrm{~L} / \mathrm{min}$ ) was blown into a $20 \mathrm{mM}$ sodium carbonate aqueous solution $(350 \mathrm{~mL}, \mathrm{pH} 11.3)$ from the $20 \mathrm{~A}$, $20 \mathrm{~V}$ plasma torch. The reaction vessel was cooled using a water jacket to maintain the reaction at $25-40{ }^{\circ} \mathrm{C}$.

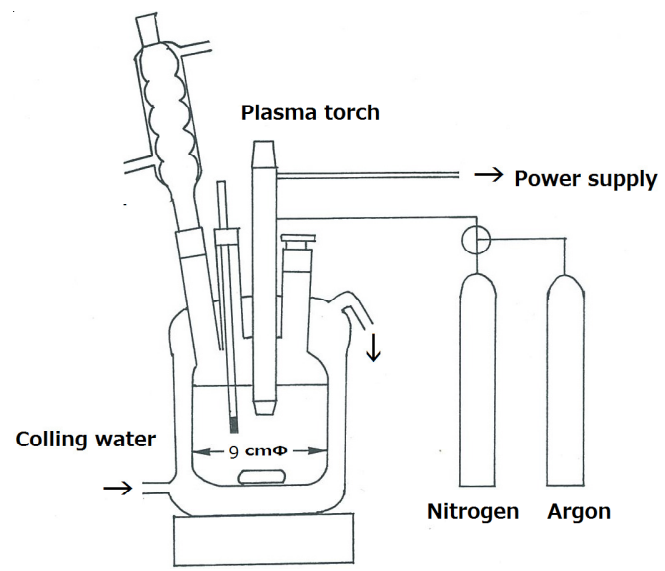

Fig. 1. Apparatus for producing the plasma jet. A jet of nitrogen-argon plasma produced from a mixture of nitrogen and argon gas was blown out of a plasma torch into an aqueous solution containing 20 $\mathrm{mM}$ sodium carbonate. The reaction vessel was cooled by water flowing in an outer cooling jacket to maintain the reaction at 25$40{ }^{\circ} \mathrm{C}$

Analytical method: Resulting concentrations of nitrate and nitrite were determined by an ion chromatography equipped with an analytical column: TSK IC-Anion-PW (50 $\mathrm{mm} \times 4.6 \mathrm{~mm}$ I.D.). Eluent: $30 \mathrm{mM}$ borate buffer $(\mathrm{pH} 3.0)$ containing $1.3 \mathrm{mM}$ potassium gluconate, $1.3 \mathrm{mM}$ pyroborate, $10 \%$ acetonitrile and $0.5 \%$ glycerin. Flow: $1.2 \mathrm{~mL} / \mathrm{min}$. Detection: absorption at $210 \mathrm{~nm}$ (Fig. 2).

A Jasco HPLC system was used for analyses of formate. Column: GL Sciences Inc. Inertsil-ODS $(250 \mathrm{~mm} \times 4.6 \mathrm{~mm}$ I.D.). Eluent: $5 \mathrm{mM}$ ammonium phosphate ( $\mathrm{pH} 2.5)$. Detection: absorption at $210 \mathrm{~nm}$. Flow rate: $0.5 \mathrm{~mL} / \mathrm{min}$ (Fig. 3).

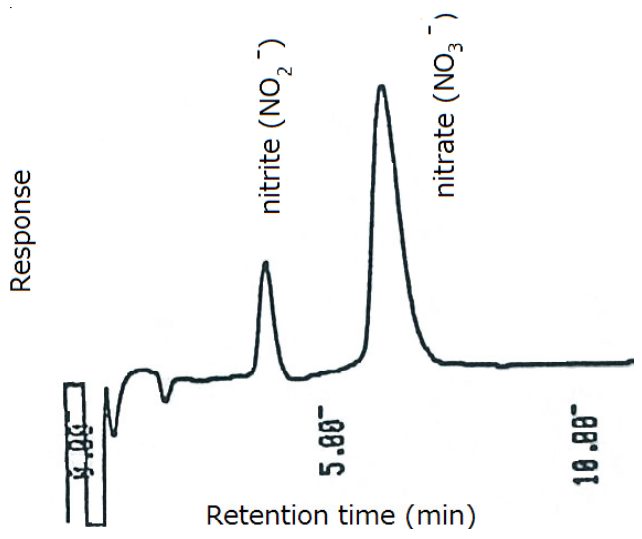

Fig. 2. Ion chromatograms of nitrate and nitrite. A Jasco HPLC system was used for the analyses. Analytical column: TSK IC-Anion-PW $(50 \mathrm{~mm} \times 4.6 \mathrm{~mm}$ I.D.). Eluent: $30 \mathrm{mM}$ borate buffer $(\mathrm{pH} \mathrm{3.0)}$ containing $1.3 \mathrm{mM}$ potassium gluconate, $1.3 \mathrm{mM}$ pyroborate, 10 $\%$ acetonitrile and $0.5 \%$ glycerin. Flow: $1.2 \mathrm{~mL} / \mathrm{min}$. Detection: absorption at $210 \mathrm{~nm}$ (a)

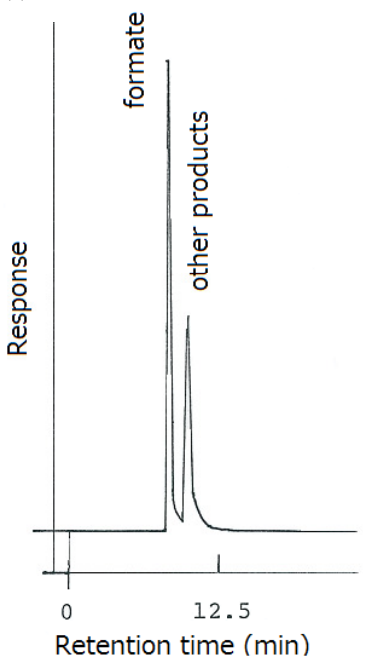

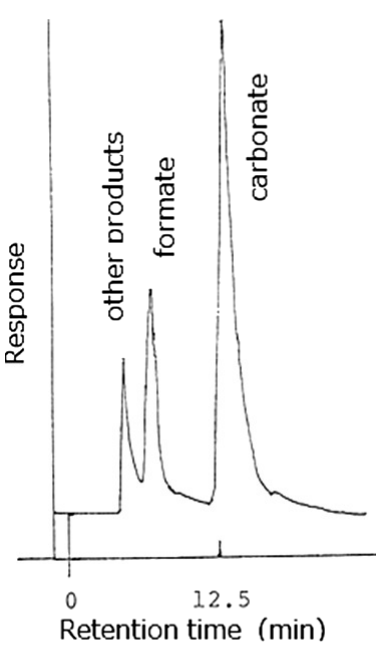

Fig. 3. Chromatograms of formate or carbonate by using a reversed column (a) and an anion exchange column (b). (a) A Jasco HPLC system was used for analyses. Column: GL Sciences Inc. Inertsil-ODS (250 $\mathrm{mm} \times 4.6 \mathrm{~mm}$ I.D.). Eluent: $5 \mathrm{mM}$ ammonium phosphate ( $\mathrm{pH} 2.5$ ). Detection: absorption at $210 \mathrm{~nm}$. Flow rate: $0.5 \mathrm{~mL} / \mathrm{min}$. (b) A Dionex ion chromatography $2000 \mathrm{i}$ was used for analyses. Column: HPICE-AS1 (250 $\mathrm{mm} \times 4 \mathrm{~mm}$ I.D.) equipped with an AFS2 anion fiber suppresser. Eluent: $0.125 \mathrm{mM}$ octane sulfonic acid. Ion removal agent: $5.0 \mathrm{mM}$ tetrabutyl-ammonium hydroxide. Flow: $0.7 \mathrm{~mL} / \mathrm{min}$. Detection: conductivity

A Dionex ion chromatography 2000i was used for analyses of formate and carbonate. Column: HPICE-AS1 $(250 \mathrm{~mm} \times 4$ mm I.D.) equipped with an AFS2 anion fiber suppresser. Eluent: $0.125 \mathrm{mM}$ octanesulfonic acid. Ion removal agent: 5.0 $\mathrm{mM}$ tetrabutyl-ammonium hydroxide. Flow: $0.7 \mathrm{~mL} / \mathrm{min}$. Detection: electric conductivity.

\section{RESULTS AND DISCUSSION}

A jet of nitrogen plasma was blown into a sodium carbonate solution $(20 \mathrm{mM})$ using different nitrogen-to-argon flow ratios. Table- 1 shows the concentration of products after 90 min. Formate and ammonia and oxidative products such as nitrite and nitrate were obtained in the reaction mixture. Formate and other compounds increased with higher ratios of 


\begin{tabular}{cccccc}
\hline \multicolumn{5}{c}{ TABLE-1 } \\
FORMATION OF NITRIC ACID, NITROUS ACID, \\
AMMONIA AND FORMATE BY BLOWING A JET OF \\
NITROGEN-ARGON PLASMA INTO AN AQUEOUS \\
SOLUTION OF SODIUM CARBONATE FOR 90 min \\
\hline \multirow{5}{*}{ Entry } & Flow rate $($ L/min) & \multicolumn{5}{c}{ Yield (mM) } \\
\cline { 2 - 6 } & $\mathrm{N}_{2}-\mathrm{Ar}$ & $\mathrm{HNO}_{3}$ & $\mathrm{NHO}_{2}$ & $\mathrm{NH}_{3}$ & $\mathrm{HCOOH}$ \\
\hline 1 & $0.0-2.0$ & 0 & 0 & 0 & 0 \\
2 & $0.5-1.5$ & 1.69 & 8.89 & 0.043 & 1.82 \\
3 & $1.0-1.0$ & 5.35 & 23.2 & 0.064 & 4.03 \\
4 & $2.0-0.0$ & 4.95 & 35.7 & 0.089 & 6.97 \\
$5^{\text {b }}$ & $2.0-0.0$ & 2.00 & 14.3 & 0.200 & - \\
\hline${ }^{\mathrm{a}}$ Flow rate of each gas used for plasma jet generator. ${ }^{\mathrm{b}} \mathrm{A}$ plasma jet ${ }^{17}$ \\
blowing in a sodium borate buffer at pH 12.7.
\end{tabular}

nitrogen to argon $(0.0,2.0 ; 0.5,1.5 ; 1.0,1.0 ; 2.0,0.0 \mathrm{~L} / \mathrm{min})$, while the compounds were not obtained when the jet did not contain nitrogen.

To our best of knowledge, this is the first reported finding of formate formation after blowing a jet of nitrogen containing plasma into a sodium carbonate solution, although research by Takasaki et al. ${ }^{14,15}$ and our research ${ }^{16,17}$ showed that ammonia, nitric acid and nitrous acid formed after using a jet of nitrogenargon plasma and contact glow discharge electrolysis. This is a typical disproportionation reaction between carbonate, water and nitrogen under high energy conditions. These results indicate that the nitrogen radical in plasma might trap $\mathrm{OH}$ radicals and that the remaining $\mathrm{H}$ radical reduced carbonate to give formate. Entry 5 shows the cited ${ }^{17}$ data in a sodium borate buffer solution at $\mathrm{pH}$ 12.7. Yields of nitrite and nitrate are rather lower and yield of ammonia is higher than the results in entry 1-4. Comparison of these data suggests that carbonate in the reaction mixture could accelerate the formation of nitrite and nitrate and depress the formation of ammonia.

Fig. 4 shows the time course of formate production using different nitrogen-to-argon flow ratios. The concentration of formate increased with time. Nitrogen clearly plays an essential role in formate production. And also nitrogen plasma gives a thermodynamically advantage to the reactions. The formation of formate from molecular nitrogen, water and carbonate is thermodynamically difficult because of the thermal disadvantage (Scheme-III). However, the high energy of nitrogen plasma activates molecular nitrogen to nitrogen radicals to result in the reductive fixation of carbonate to formate with a little exothermal energy formation (Schemes IV and V).

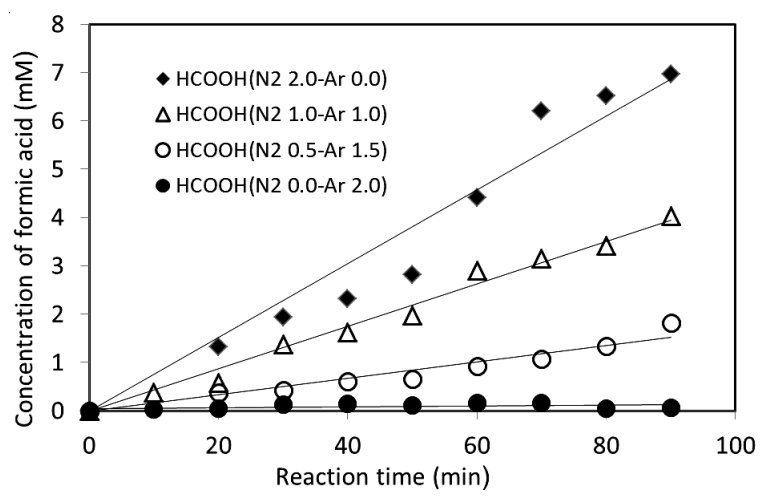

Fig. 4. Formation of formate by blowing a jet of nitrogen-argon plasma into $20 \mathrm{mM}$ sodium carbonate. Plasma jet conditions: nitrogenargon flow: $0.0-2.0 ; 0.5-1.5 ; 1.0-1.0 ; 2.0-0.0 \mathrm{~L} / \mathrm{min}$. Current and voltage: $20 \mathrm{~A}$ and $20 \mathrm{~V}$; reaction temperature $25-40^{\circ} \mathrm{C}$

$$
\begin{aligned}
& \mathrm{N}_{2}+\mathrm{H}_{2} \mathrm{O}+(7 / 2) \mathrm{H}_{2} \mathrm{CO}_{3} \longrightarrow(1 / 2) \mathrm{HNO}_{3}+(3 / 2) \mathrm{HNO}_{2}+(7 / 2) \mathrm{HCOOH} \\
& \Delta \mathrm{G}^{\circ}{ }_{298}=976 \mathrm{~kJ} / \mathrm{mol} \\
& \mathrm{N}_{2} \longrightarrow \quad 2 \mathrm{~N} \cdot \quad \Delta \mathrm{G}^{\circ}{ }_{298}=911 \mathrm{~kJ} / \mathrm{mol} \\
& \text { Scheme-IV } \\
& 2 \mathrm{~N}^{\cdot}+\mathrm{H}^{\cdot}+\cdot \mathrm{OH}+(7 / 2) \mathrm{H}_{2} \mathrm{CO}_{3} \longrightarrow(1 / 2) \mathrm{HNO}_{3}+(3 / 2) \mathrm{HNO}_{2}+(7 / 2) \mathrm{HCOOH} \\
& \Delta \mathrm{G}^{\circ}{ }_{298}=-410 \mathrm{~kJ} / \mathrm{mol}
\end{aligned}
$$

Fig. 5 shows the decrease of carbonate and yield of formate in the solution after reaction with the nitrogen plasma for a longer time. The decrease in carbonate is similar to the increase of formate. After $420 \mathrm{~min}(7 \mathrm{~h})$, formate reached a more than $80-90 \%$ yield. When argon gas alone $(2.0 \mathrm{~L} / \mathrm{min})$ was used for the reaction, formate was not detected on the ion chromatograms. These findings suggest the strong possibility of formation of formate from carbonate in the primitive ocean by nitrogen plasma in nature. The reductive reactions could have produced various reducing organic compounds and ammonia in the primitive ocean under a nonreducing atmosphere $\left(\mathrm{N}_{2}, \mathrm{CO}_{2} \text { and } \mathrm{H}_{2} \mathrm{O}\right)^{9}$. The effectiveness of nitrogen and carbon dioxide was also discussed by Rode and coworkers ${ }^{19,20}$ after they found organic compounds such as simple amino acids in the electric discharge on the junction between the gaseous and aqueous phases of water when sparging with nitrogen and carbon dioxide. Although the mechanism was not discussed in detail, their results support the effectiveness of an active nitrogen species derived from molecular nitrogen in the primitive water sphere.

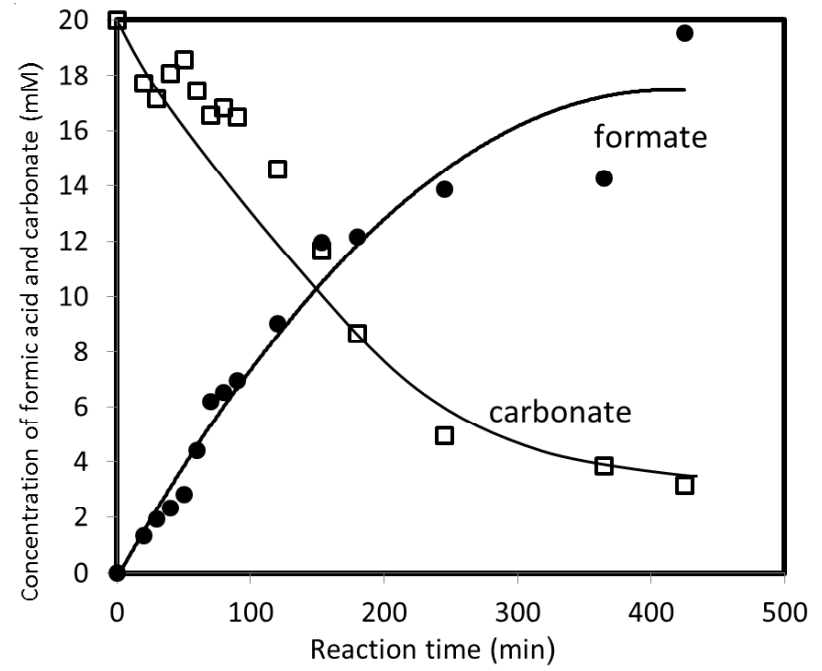

Fig. 5. Formation of formate by blowing a jet of nitrogen-argon plasma into $20 \mathrm{mM}$ sodium carbonate. Plasma jet conditions: nitrogenargon flow, 2.0-0.0 L/min. Current and voltage: $20 \mathrm{~A}$ and $20 \mathrm{~V}$; reaction temperature $25-40{ }^{\circ} \mathrm{C}$

However, Tiang et al. ${ }^{21,22}$ recently showed that the escape of hydrogen from primitive earth was much slower than that previously assumed. Chyba discussed ${ }^{23}$ the effect of a higher concentration of hydrogen on the formation of carbon compounds. They proposed a more reducing atmosphere containing a higher concentration of hydrogen than that believed by many 
researchers until recent years. They also discussed the relationship between the yield of organic compounds and the hydrogencarbon ratio, but not the effect of nitrogen concentration. The effect of nitrogen ${ }^{24}$ in relation to organic compound formation should be further discussed. Although a reducing atmosphere would likely facilitate the formation of organic compounds, our results have demonstrated their formation regardless of reductive conditions, although formation of organic compounds in a nonreducing atmosphere is more difficult.

\section{Conclusion}

The results shown here demonstrate that formate could be produced from carbonate anions by the action of nitrogen plasma in the primitive ocean under nonreducing conditions. To our best of knowledge, this study is the first clear example of organic compound formation in high yield from inorganic compounds without iron under a nonreducing atmosphere. The chemical action of nitrogen plasma in aqueous solution is now under further investigation.

\section{REFERENCES}

1. S.L. Miller, Science, 117, 528 (1953)

2. W.W. Rubey, Bull. Geol. Soc. Am., 62, 1111 (1951).

3. P.H. Abelson, Proc. Nat. Acad. Sci. USA, 55, 1365 (1966).
4. A. Anderson-Sellers and A.J. Meadows, Nature, 270, 589 (1977).

5. T. Owen, R.D. Cess and V. Ramanathan, Nature, 277, 640 (1979).

6. R.A. Kerr, Science, 210, 42 (1980).

7. R. Stribling and S. Miller, Origins Life, 17, 261 (1987).

8. W. Löb, Z. Elektrochem., 15, 282 (1906).

9. W. Groth and H. Suess, Naturwiss, 26, 77 (1938).

10. W.M. Garrison, D.C. Morrison, J.G. Hamilton, A.A. Benson and M. Calvin, Science, 114, 416 (1951).

11. C.E. Folsome, A. Brittain, A. Smith and S. Chang, Nature, 294, 64 (1981).

12. H. Hase, T. Saito and K. Harada, Viva Origino, 29, 63 (2001).

13. H. Hase and K. Harada, Viva Origino, 29, 61 (2001).

14. M. Takasaki and K. Harada, Chem. Lett., 16, 365 (1987).

15. M. Takasaki and K. Harada, Chem. Lett., 16, 437 (1987).

16. K. Harada, M. Takasaki, S. Igari, T. Munegumi and A. Shimoyama, Proceedings of 8th International Symposium on Plasma Chemistry, p. 654 (1987).

17. T. Munegumi and K. Harada, Viva Origino, 23, 189 (1995).

18. I. Yamakawa, Y. Ito, T. Munegumi and K. Harada, Bull. Chem. Soc. (Japan), 83, 1264 (2010).

19. B. Schranz and B.M. Rode, Angew. Chem. Ind. Ed., 43, 1886 (2004)

20. B.M. Rode, D. Fitz and T. Jakschitz, Chem. Biodiv., 4, 2674 (2007).

21. F. Tiang, O.B. Toon, A.A. Pavlov and H. De Sterck, Science, 308, 1014 (2005).

22. F. Tiang, O.B. Toon and A.A. Pavlov, Science, 311, 38b (2006).

23. C.F. Chyba, Science, 308, 962 (2005)

24. D.E. Canfield, A.N. Glazer and P.G. Falkowski, Science, 330, 192 (2010). 